\title{
Chaining, culture and values: ethical issues in research in middle- and low-income countries ${ }^{\dagger}$
}

\author{
Julian C. Hughes
}

\begin{abstract}
Summary
A paper in this month's British Journal of Psychiatry reports on research from Ghana where some participants were exposed to chaining, which raises ethical concerns. Strict boundaries need to exist between researchers and cruel, inhuman or degrading treatment. Nevertheless, there may be things we can learn from other cultures about our own values.
\end{abstract}

\section{Declaration of interest}

None.

\section{Copyright and usage}

(c) The Royal College of Psychiatrists 2018
Julian C. Hughes is RICE Professor of Old Age Psychiatry at the University of Bristol and Deputy Chair of the Nuffield Council on Bioethics.

The reality of being chained up against your will must be appalling. The notion of dignity springs to mind, but perhaps this is because 'dignity' is currently overused. Loss of dignity can result from not having your shirt tucked in properly, whereas being chained for days is much more than that, although it is also undignified. Being chained up sounds more like torture. So, a question springs to mind: if you undertake research that involves chaining (let alone starvation), is this like undertaking research that involves torture?

\section{Background}

To ask this question in connection with the interesting research undertaken by Ofori-Atta and colleagues ${ }^{1}$ might seem gratuitously insulting. For those who have not yet read the paper it is a report of an experiment to determine whether treatment using psychotropic medication is better than standard treatment for people with mental disorders in a prayer camp in Ghana, where standard treatment involves chaining and fasting. I want to use the question about torture to draw out some ethical and philosophical issues.

My impression is that the authors, working in a challenging environment, have been acutely aware of the ethical quagmire that surrounds their research. Their intentions were good and, overall, the people in the prayer camp benefited from their presence. This research, in a context that seems far removed from psychiatric practice in Western high-income countries, poses challenges to (what might be considered) more enlightened thinking and practice.

\section{Some casuistic thinking}

Talk of torture might seem egregious. But it allows us to pursue a casuistic thought: to compare a case we would be certain about with a similar case, to ask what the essential moral differences might be. ${ }^{2}$ We can be certain that doctors should not participate in torture. The Declaration of Tokyo states: 'The physician shall not countenance, condone or participate in the practice of torture

† See pp. 6-8 and 34-41, this issue. or other forms of cruel, inhuman or degrading procedures....' We would have to say, therefore, that working alongside torturers, albeit taking no part in the decisions to torture, in order to change the torturers' habits by allowing them to witness how effective non-torture might be, would be completely unethical. What are the key moral differences between this and the work of Ofori-Atta et al in the prayer camps?

We can argue that chaining in the prayer camps does not amount to torture. This, however, could be contested. In Article 1.1 of the United Nations (UN) Convention on Torture, ${ }^{4}$ it defines torture as: any act that involves severe mental or physical pain or suffering which is intentionally inflicted on a person to obtain information, or a confession, or to act as a punishment, and so on. None of this seems relevant to chaining in the context of the prayer camps (at least, not as described). But it also mentions coercion and that the pain and suffering might be applied 'for any reason based on discrimination of any kind'.

It could be said that, even if it is not torture, chaining is a cruel, inhuman and degrading treatment, which also falls under the remit of the UN Convention. And recall that the Declaration of Tokyo was aimed at 'other forms of cruel, inhuman or degrading procedures' too. In fact, the distinction between 'torture' and 'cruel, inhuman or degrading procedures' is not completely clear. In Ireland $v$. the United Kingdom it was judged that the distinction was legally significant and rested on 'a difference in the intensity of the suffering inflicted'. ${ }^{5}$ Alternatively, it can be argued that the intention (to gain information or a confession and so on) marks out torture as opposed to treatment which is 'merely' cruel, inhuman or degrading. But either way, healthcare should have nothing to do with anything that even sniffs of torture; and cruel, inhuman or degrading treatment has that smell.

Let us accept that chaining is a cruel, inhuman and degrading way to treat people. Yet there is still the issue of whether or not this 'treatment' is based on any kind of discrimination. An important feature of casuistry is that it calls for immersion in the facts of the particular case. It is certainly not obvious that the prayer camp (as described) is based on discrimination. Nor is it obvious that chaining is a matter of discrimination, since it is not used on all people entering the camp with a mental illness, but only on those who are agitated or likely to self-harm. That is, it could be argued that chaining is based on two of the well-known principles of medical ethics: beneficence and non-maleficence. ${ }^{6}$ It would be harder to mount an argument that chaining was in accordance with the principle of respect for autonomy. However, the notions of 'precedent' autonomy (what the person would have wanted 
prior to (and putatively after) an episode of mental disorder) and 'relational' autonomy (recognition that the person does not make decisions in isolation) allow some wiggle room.

Hence, it is not clear that researchers should stay away from chaining (or similar practices) in the same way that they should stay away from torture. Although it is clear, too, that - as in the research of Ofori-Atta et al - strict boundaries need to be observed so that there is no odour of collusion with cruel, inhuman and degrading treatments.

\section{Consent and cultural imperialism}

It seems reasonable to question whether someone who is illiterate and disturbed enough by a mental disorder to be taken to a Ghanaian prayer camp has the ability to give valid consent. Ignoring the fact that in many jurisdictions it would not be possible for one adult to consent on behalf of another, it is similarly reasonable to question whether the families of illiterate patients are any better placed to give 'consent', even when the information about the research is read out to them. If you take your loved one for treatment in a prayer camp, is this because you have no other option in terms of treatment, or is it because you believe in the efficacy of prayer and accept the need for occasional chaining? And in this population, would and should informed consent involve understanding risks such as neuroleptic malignant syndrome and hyponatraemia?

We can raise questions, therefore, about the adequacy of the consent procedure. But there is a question about the questions, which is, do they represent a form of cultural imperialism? Is it right that, in judging research in the sort of environment we are considering, we should insist on the same ethical standards that would be applied in a high-income country? Might this not make it impossible to carry out certain sorts of research, or at least impossible to get the research reported in a high-impact journal concerned about reputational risk? Thus, Western ethics might stifle innovative research in low- and middle-income countries.

Nevertheless, first, it can also be argued that 'Western ethics' is in danger of stifling research in high-income countries. For instance, the realities of gaining consent in an elderly population living with dementia in care homes in the UK can make the stringent demands of a UK research ethics committee seem obtuse. Second, we should respect the legitimacy of local research ethics committees who are more likely to understand the realities on the ground in their own countries; but if we do not respect their judgements, we should raise this with them. Third, it may well be that our own standards need to be challenged: think of the kerfuffle in England and Wales over deprivation of liberty safeguards.

In any case, 'cultural imperialism' is a contested notion and Tomlinson suggested that, whereas in the past 'imperialism' connoted power, now - given uncertainty and loss of moral legitimacy in the West - cultural imperialism can be thought of as 'a process of loss.' He opines that instead of 'imperialism' we should think of 'globalisation', which 'suggests interconnection and interdependency. ${ }^{7}$ We might wish to consider both that encouraging other nations to consider our (individualistic) values is not wrong and that we should learn from moral stances that place greater weight than we do on, for instance, family and community.

\section{Values and voices}

Indeed, we must recognise the need to respect deeply held values, even when they are different to our own. Some things will be out of bounds, such as torture, but there are likely to be shared values too, such as religious beliefs. Negotiating shared and diverse values is the stuff of values-based practice. ${ }^{8}$ As a recent series of articles in the British Journal of Psychiatry - International on coercion made plain, chaining is ubiquitous and restraint is certainly not confined to low- and middle-income countries. ${ }^{9}$ Values-based practice encourages us to hear the voices of those who have used our services. We need to understand their perspectives and values too. ${ }^{10}$ This should apply, of course, to the survivors of chaining in prayer camps as well.

\section{Conclusion}

If we wish to improve mental healthcare worldwide, we shall need to engage with practices that will test our ethical inclinations. Boundaries in research will have to be maintained with integrity. But we should not presume that our own ethical intuitions are sacrosanct. Practice can be changed by evidence and by law. But we also change hearts and minds by example and by dialogue.

Julian C. Hughes, MA, PhD, FRCP Edin, FRCPsych, The RICE Centre, Royal United Hospital, Combe Park, Bath BA1 3NG, UK. Email: julian.hughes@bristol.ac.uk

First Received 30 August 2017, accepted 21 September 2017

\section{References}

1 Ofori-Atta A, Attafuah J, Jack H, Baning F, Rosenheck R and the Joining Forces Research Consortium. Joining psychiatric care and faith healing in a prayer camp in Ghana: randomised trial. Br J Psychiatry 2018; 212: 34-41.

2 Louw SJ, Hughes JC. Moral reasoning - the unrealized place of casuistry in medical ethics. Int Psychogeriatr 2005; 17: 149-54.

3 World Medical Association. WMA Declaration of Tokyo - Guidelines for Physicians Concerning Torture and Other Cruel, Inhuman or Degrading Treatment or Punishment in Relation to Detention and Imprisonment. WMA, 2016 (https://www.wma.net/policies-post/wma-declaration-of-tokyo-guidelines-for-physicians-concerning-torture-and-other-cruel-inhuman-or-degrading-treatment-or-punishment-in-relation-to-detention-and-imprisonment/).

4 United Nations. Convention against Torture and Other Cruel, Inhuman, Degrading Treatment or Punishment. UN, 1984 (http://www.un.org/ga/search/ view_doc.asp?symbol=a/res/39/46).

5 Ireland v. United Kingdom (Irish State Case), 25 Eur. Ct. H.R. (Ser. A) (1978), paragraphs $167-8$.

6 Gillon R. Medical ethics: four principles plus attention to scope. Br Med J 1994; 309: $184-8$.

7 Tomlinson J. Cultural Imperialism: A Critical Introduction. Johns Hopkins University Press, 1991: 174-5.

8 Fulford KWM, Peile E, Carroll H. Essential Values-Based Practice-Clinical Stories linking Science with People. Cambridge University Press, 2012.

9 Molodynski A, O'Brien A, Burns J. Key international themes in coercion. BJPsych International 2017; 14: 61-3.

10 Rose D, Perry E, Rae S, Good N. Service user perspectives on coercion and restraint in mental health. BJPsych International 2017; 14: 59-61. 